\title{
Sporcularda Optimal Performans Duygu Durumu: Ruminatif Düşünce ve Akıldışı İnançların Rolü Üzerine Bir Çalışma
}

\author{
Flow in Athletes: A Study on the Role of Ruminative Thought and Irrational Beliefs
}

\begin{abstract}
${ }^{1}$ H. Feyzanur AKSOY
${ }^{2}$ F. Hülya AŞÇI

${ }^{1}$ Marmara Üniversitesi, Egzersiz ve Spor Psikolojisi Bölümü

${ }^{2}$ Marmara Üniversitesi, Spor Bilimleri Fakületsi, Beden Eğitimi ve Spor Bölümü
\end{abstract}

\section{Yazışma Adresi \\ Corresponding Address:}

\section{H. Feyzanur Aksoy}

ORCID No: 0000-0002-6232-2035

Marmara Üniversitesi Egzersiz ve Spor Psikolojisi Bölümü

E-posta: feyzanuraksoy@ gmail.com

\section{öz}

Bu çalışmanın amacı sporcularda ruminatif düşünce ve akıldışı inançların optimal performans duygu durumunu belirlemedeki rolünü araştırmaktır. Çalışmaya İstanbul ilinde bireysel spor ve takım sporu yapan 133 kadın ( $X_{\text {yaş: }}$

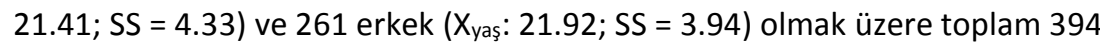
sporcu (Xyaş: 21.75; SS = 4.07) katılmıştır. Sporculara "Kişisel Bilgi Formu", "Ruminatif Düşünce Biçimi Ölçeği", "Akıldışı Performans İnançları Envanteri2" ve "Sürekli Etkinlik Tecrübe Ölçeği Kısa Formu (SDFS-2)" uygulanmıştır. Yapılan hiyerarşik regresyon analizi sonuçlarına göre, ruminatif düşünce optimal performans duygu durumunun anlamlı belirleyicisi değildir ( $p>0.05)$. Elde edilen bulgular, sporcuların akıldışı inanç düzeylerinin optimal performans duygu durumunu anlamlı olarak yordadı̆̆ını göstermektedir $(p<0.05)$. Akıldışı inanç alt boyutlarından düşük tolerans ile optimal performans duygu durumu arasında anlamlı pozitif ilişki bulunmuştur ( $\beta=0.22$; $\mathrm{p}<0.05)$. Sonuç olarak; sporcuların zihnini meşgul eden tekrarlayıcı içsel düşünceler, sporcuların yaptığı aktivite ile özdeşleşip göreve odaklanmaları ile ilişkili değilken; sporcularda başarısızlığa ve belirlenen hedeflere ulaşamamaya karşı tahammülsüzlüğü ifade eden akıldışı inanç alt boyutlarından düşük toleransın, sporcuların optimal performans duygu durumunu belirlemede rol oynadığı görülmektedir.

Anahtar Kelimeler: Optimal performans duygu durumu, Ruminatif düşünce, Akıldışı inançlar

\section{ABSTRACT}

The aim of this study was to investigate the role of ruminative thoughts and irrational beliefs in determining flow in athletes. One hundred thirty three female ( $M=21.41 ; S D=4.33$ age) and 261 male ( $M=21.92 ; S D=3.94$ age), in total 394 ( $M=21.75 ; S D=4.07$ age) athletes participated in this study. "Demographic Information form", "Ruminative Thought Style Questionnaire", "Irrational Performance Beliefs Inventory-2", and "Short Dispositional Flow Scale-2" were administered to participants. The results of hierarchical regression analysis indicated that ruminative thought was not a significant determinant of flow experiences ( $p>0.05)$. On the other hand, the irrational belief of the athletes significantly predicted the flow experiences $(p<0.05)$. A significant positive correlation was found between low frustration tolerance sub-scales of irrational belief and flow experiences $(\beta=0.22 ; p<0.05)$. In conclusion, the ruminative thoughts that occupy the minds of the athletes are not related to the athletes' identification with their activity and focusing on the task; it is seen that low tolerance, one of the sub-scales of irrational belief, which expresses intolerance to failure and inability to reach the determined goals in athletes, play a significant role in determining flow experiences of athletes.

Keywords: Flow, Ruminative thoughts, Irrational beliefs. 


\section{GíRIŞ}

Hızla gelişen bir bilim alanı olan egzersiz ve spor psikolojisi alanyazınında farklı psikolojik kavramların sporcuların performanslarına etkisi incelenmektedir (Crust ve Swann, 2011). Bu kavramlardan biri pozitif psikoloji alanında da ele alınan optimal performans duygu durumudur. Optimal performans duygu durum (flow) Türkçe alanyazında akış deneyimi olarak da adlandırılmaktadır.

Csikszentmihalyi'nin 1975 yılında yayımlandığı "Beyond Boredom \& Anxiety" adlı kitabında optimal performans duygu durum kavramı kişileri serbest zaman aktivitelerine yönelten nedenleri belirtmek amacı ile kullanılmıştır. Csikszentmihalyi (1975) farklı meslek gruplarından bireyler ile yaptığı görüşmelerde; katılımcıların zamanlarının çoğunu aktivitelerine adadıklarını, bu aktivitelerden kazandıkları deneyimin çok özel bir durum olduğunu belirtmiştir. Günlük yaşamda kolay ulaşılmayan bir durum olarak ele alınan optimal performans duygu durumu bireylerin harekete tamamen katılma durumlarında hissettikleri bütüncül bir duygudur (Csikszentmihalyi, 1975). Bir işle yoğun olarak ilgilenme ve haz alma olarak tanımlanan optimal performans duygu durumu, düşüncelerin, amaçların, duyguların ve tüm duyuların aynı hedefe odaklanmasını içerir (Csikszentmihalyi, 1990). Bireyler, beceriler ve zorlukların yüksek seviyede ve dengede olduğu durumlarda optimal performans duygu durumunu deneyimlerler (Jackson ve Csikzsentmihalyi, 1999).

Spor ve egzersiz ortamında optimal performans duygu durumu kişilerin fiziksel aktivite/spor sırasında sergiledikleri becerileri ile o anda algılanan durum, gereklilikler veya mücadele arasında sağladıkları denge sonucunda oluşan optimal zihinsel durumu ifade eder (Jackson ve Eklund, 2004). Yüksek optimal performans duygu durumuna sahip sporcuların, düşük optimal performans duygu durumuna sahip olanlara göre, pozitif duygularında artış olması ve performanslarını olumlu etkilemesi optimal performans duygu durumunun spordaki önemini ortaya koymaktadır (Rogatko, 2009).

Araştırmacılar tarafından spor ve egzersiz ortamında optimal performans duygu durumunu etkileyen faktörler sıklıkla ele alınmıştır. Bir araştırmaya göre (Swann ve diğ., 2012), sürdürülebilir odaklanma, fiziksel hazırlık, takım arkadaşı ile bütünlük, olumlu zihinsel tutum, yarışma öncesi ve yarışma sırasında yaşanan olumlu sonuçlar gibi faktörler optimal performans duygu durumunu olumlu; fiziksel problemler/ hatalar, odaklanmayı sürdürmedeki yetersizlik ve olumsuz zihinsel tutum gibi faktörler ise olumsuz etkilemektedir. Ayrıca güdülenme, uygun uyarılma seviyesi, zihinsel hazırlık, odaklanma, kendine güven, çevresel ve durumsal koşullar ve yoğunlaşma optimal performans duygu durumunu olumlu yönde etkileyen faktörlerdendir (Jackman ve diğ., 2014; Swann ve diğ., 2014). Öte yandan, kaygı (Stavrou ve diğ., 2007), motivasyon eksikliği ve olumsuz geri bildirim (Swann ve diğ., 2012) gibi psikolojik yapıların optimal performans duygu durumunu etkileyen olumsuz faktörler olduğu belirtilmiştir. Wiggins ve Freeman (2000)'a göre kaygı seviyesi daha düşük ve hissedilen kaygıyı destekleyici olarak algılayan sporcular, kaygı seviyesi yüksek ve hissedilen kaygıyı zorlaştırıcı algılayan sporculardan daha kolay optimal performans duygu durumu deneyimi yaşayabilmektedir.

Güdülenme ile optimal performans duygu durumu arasındaki ilişki de egzersiz ve spor psikolojisi alanyazınında sıklıkla ele alınmıştır. Bu ilişkiyi irdeleyen çalışmalar hem hür irade hem de başarı hedefi yaklaşımına dayalı olarak gerçekleştirilmiştir. Hür irade kuramı çerçevesinde yapılan çalışmalarda içsel güdülenmenin optimal performans duygu durumu ile pozitif ilişkili olduğu, güdülenmemenin ise negatif ilişkili olduğu belirtilmiştir (Altıntaş ve diğ., 2013). Başarı hedefi yaklaşımı çerçevesinde yapılan çalışmalar genel olarak görev ve ego hedef yönelimleri ve algılanan güdüsel iklimin optimal performans duygu durumu ile pozitif ilişkili olduğunu ortaya koymaktadır (Jackson ve Roberts, 1992; Cervello ve diğ., 2006; Murcia ve diğ., 2008; González-Cutre ve diğ., 2009; Ada ve diğ., 2018). Örneğin, optimal performans duygu durumunun, görev yönelimi, algılanan yeterlik ve yüksek performans ile olan ilişkisinin araştırıldığı çalışmada; 
Jackson ve Roberts (1992) görev yönelimi yüksek olan sporcuların yüksek algılanan yeterliğe sahip olmalarından dolayı, optimal performans duygu durumunu daha fazla yaşama ihtimallerinin olduğunu belirtmişlerdir.

Kişilik ile optimal performans duygu durumu arasındaki ilişki de alanyazında ele alınmıştır. Örneğin, Ullén ve diğg. (2012) depresif, sinirli ve kaygılı kişilerin optimal performans duygu durumunu yaşama ihtimallerinin düşük olduğunu; çalışkan, azimli ve kontrollü kişilerin ise optimal performans duygu durumunu daha kolay yaşadıklarını bulmuşlardır. Gözmen ve Aşçı (2016) ise elit sporcularda yaptıkları çalışma ile gelişime açıklık ve öz denetim kişilik özelliklerinin optimal performans duygu durumunun yordayıcısı olduğu sonucuna ulaşmışlardır.

Alanyazında yer alan yukarıda bahsedilen çalışmalara bakıldığında, optimal performans duygu durum ile daha çok güdülenme, kaygı ve kişilik gibi psikolojik yapıların ele alındığı görülmektedir. Optimal performans duygu durumu ile bilişsel ve düşünsel süreçlerin ilişkisinin alanyazında çok fazla ele alınmadığı görülmektedir. Bilişsel süreçlerin sporda performans üzerinde etkili olmasından dolayı (Aras ve diğ., 2020), dikkat, bilişsel kaygı, ve olumlu düşünce gibi birçok farklı bilişsel faktör spor alanında inceleme konusu olmuştur (Hamilton ve Schutte, 2016; Jackson ve Roberts, 1992; Swann ve dĭg., 2012). Spor alanında sıklıkla çalışılan bir kavram olan optimal performans duygu durumu da bilişsel ve düşünsel süreçlerden etkilenen bir kavramdır (Moneta, 2004). Optimal performans duygu durumu kişinin derin bir şekilde görev odağını ve bilişsel yeterliğini hissetmesini içerir ve göreve odaklanma, güdülenme ve aktivite kontrolünün tamamen hissedilmesinde ortaya çıkan bir zihin durumudur (Moneta, 2004; Asakawa, 2004). Bu bağlamda çalışmada optimal performans duygu durumu, bilişsel süreçleri içeren ruminatif düşünce ve akıldışı inanç kavramları ile birlikte ele alınmıştır.

Ruminatif düşünce, genellikle tek bir durum hakkında olan, düşünmeyi gerektirmeyen zamanlarda dahi zihinde tekrarlayan bilinçli düşünce biçimi olarak tanımlanır (Martin ve Tesser, 1996). Ruminatif düşüncelerin yapısında istemsiz bir şekilde meydana gelmek ve bireyin dikkatini beklenmedik ve ani bir şekilde sıkıntı verici durumlara yöneltmek vardır. Bu yapısıyla ruminatif düşünceler öfke, empati, depresyon ve kaygı gibi birçok duygu ve düşünce üzerinde tetikleyici rol oynamaktadır (Burnette ve diğ., 2009; Ysseldyk ve diğ., 2007; Josefsson ve diğ., 2017). Bunun yanı sıra kişilik, dikkat ve bilinçli farkındalık ruminatif düşünceyi etkileyen kavramlardır (Flett ve diğ., 2016; Josefsson ve diğ., 2017). Örneğin, bilinçli farkındalığın, ruminasyonda azalmaya ve olumsuz duyguları düzenleme kapasitesinin artmasına neden olduğu bilinmektedir (Josefsson ve diğ., 2017). Odaklanma ve dikkatin düzenlenmesinin optimal performans duygu durumunda oynadığı kritik rol göz önüne alındığında (Jackson ve Csikszentmihalyi, 1999; Swann ve diğ., 2012; Jackman ve diğ., 2014), bu kavramlar arasında dikkate dayalı bir ilişki kurulabileceği düşünülmüştür.

Akıldışı inanç kavramı ise gerçeklikle tutarlı olmayan, mantıksız, katı, taleplere odaklanan, hatalı çıkarımların ürünü olan, aşırı genellemeleri içeren ve bireysel hedeflere ulaşmayı engelleyen inançlar olarak tanımlanır (Dryden ve Branch, 2008). Akılcı Duygusal Davranış Terapisi’ne göre bireylerin olaylarla ilgili inanışları onlarda gelişen duygu ve davranışları belirlemektedir ve akıldışı inançlar işlevsel olmayan duyguların ve uyumsuz davranışların ortaya çıkmasına neden olmaktadır (DiGiuseppe ve David, 2015). Spor ortamında sporcuları etkileyen birçok faktör bulunmaktadır. İyi performans sergileme, antrenörü ve ailesi tarafindan beğenilme, taraftar etkisi, takdir edilme isteği ve maddi beklentiler gibi baskı unsurları bulunmaktadır. Bunlar gibi birçok faktör sporcuların akıldışı inançlar geliştirmesine neden olabilmektedir (Urfa ve Aşçı, 2018). Geliştirilen akıldışı inançlar ise işlevsel olmayan duyguların ve uyumsuz davranışların ortaya çıkmasına neden olmaktadır (Ellis ve dĭğ., 2009). Olumsuz duygu ve düşüncelerin optimal performans duygu durumunu engelleyen faktörler içinde yer aldığı bilinmektedir (Swann ve diğ., 2012; Jackman, 2019). Bu nedenle akıldışı inançlar ve optimal performans duygu durumu ilişkisi incelemeye değer bulunmuştur. 
$\mathrm{Bu}$ bilgilerden yola çıkarak optimal performans duygu durumu, ruminatif düşünce ve akıldışı inanç kavramları arasındaki ilişkinin incelenmesinin sporcuların performans gelişimine katkı sağlayacağı ve spor psikolojisi alanındaki araştırmalara derinlik kazandıracağı düşünülmektedir. Ayrıca daha önce optimal performans duygu durumu ile birlikte ele alınmamış olan ruminatif düşünce ve akıldışı inanç kavramları bu çalışmada ele alınmış ve optimal performans duygu durumu ile ilişkileri ayrı ayrı incelenmiştir. Özellikle de ülkemizde spor alanında ruminatif düşünce ve akıldışı inanç kavramları ile ilgili çalışmaların bulunmaması bu çalışmaya yön vermiştir.

$\mathrm{Bu}$ bağlamda çalışmanın amacı ruminatif düşünce ve akıldışı inanç kavramlarının optimal performans duygu durumunu belirlemedeki rolünü araştırmaktır.

\section{YÖNTEM}

Örneklem: Araştırmanın örneklemi olasılıksız örneklem yöntemlerinden uygun örnekleme yöntemi kullanılarak belirlenmiştir. Çalışmaya 18-35 yaş arası, en az 2 yıl spor deneyimine sahip ve 2019-2020 sezonunda İstanbul ilinde yarışan, bireysel spor (atletizm, boks, güreş, halter, karate, okçuluk, tekvando, tenis, yüzme) ve takım sporu (basketbol, futbol, hentbol, voleybol, ragbi, sualtı hokeyi) yapan 133 kadın (Xyaş: 21.41; SS=4.33) ve 261 erkek (Xyaş: 21.92; SS= 3.94) olmak üzere toplam 394 sporcu (Xyaş:21.75; SS=4.07) katılmıştır. Sporcuların spor deneyimi ortalaması 8.73 \pm 4.59 yıldır. Verilerin analizinden önce çalışmaya katılan sporcular spor deneyimine göre iki gruba ayrılmıştır. Birinci grup 29 yıl, ikinci grup 10 yıl ve üstü deneyimi olan sporculardan oluşmaktadır. Gruplandırma Gladwell'in (2008) 10 bin saat çalışma kriteri dikkate alınarak yapılmıştır.

\section{Veri Toplama Araçları:}

Kişisel bilgi formu: Çalışmaya katılan sporcuların yaş, cinsiyet, spor türü, spor deneyimi, millilik durumu, antrenman sıklığı gibi özelliklerini belirlemek amacıyla araştırmacılar tarafından hazırlanan Kişisel Bilgi Formu kullanılmıştır.

Sürekli etkinlik tecrübe ölçeği kısa formu (SDFS-2): Sporda algılanan sürekli optimal performans duygu durumu/akış deneyimini ölçmek amaciyla Jackson ve diğ. (2008) tarafindan geliştirilen ölçek, Çağlar ve diğ. (2020) tarafından Türkçe'ye uyarlanmıştır. Ölçek 9 maddeden oluşmakta ve tek faktörlüdür. 5'li likert tipindeki ölçeğin likert seçenekleri "Hiçbir zaman (1), Nadiren (2), Bazen (3), Sık sık (4), Her zaman (5)" şeklinde sıralanmakta ve puanlaması bu şekilde yapılmaktadır. Ölçeğin Türkçe formuna ait iç tutarlık katsayısı 0.77 (Çağlar ve diğ., 2020)'dir. Bu çalışma örneklemine ait iç tutarlık katsayısı Çağlar ve dĭg. (2020) tarafından yapılan çalışmaya benzer şekilde 0.77 olarak bulunmuştur.

Ruminatif düşünce biçimi ölçeği: Ruminatif Düşünce Biçimi Ölçeği, Brinker ve Dozois (2009) tarafindan geliştirilmiştir. Ölçek ruminatif düşünce biçimlerini değerlendirmek amacı ile geliştirilmiştir ve Martin ve Tesser’in ruminasyon teorisine dayalıdır. Bu kapsamda geliştirilen ölçek, kontrol edilemeyen, geri-dönüşlü, girici ve tekrarlayan olmak üzere 4 temel ruminatif düşünce özelliğini değerlendirmektedir. Ölçek tek faktörlü ve 20 maddeden oluşmaktadır. Katılımcıların, ölçek maddelerindeki ifadeleri 1 (beni hiç tariflemiyor) ile 7 (beni çok iyi tarifliyor) arasında değerlendirmeleri istenmektedir. Ölçek, Karatepe ve diğ. (2013) tarafından Türkçeye uyarlanmıştır. Ölçeğin Türkçe formuna ait iç tutarlık katsayısı 0.90’ dır (Karatepe ve diğ., 2013). Bu çalışma örneklemine ait iç tutarlık katsayısı 0.93 olarak bulunmuştur.

Akıldışı performans inançları envanteri-2: Akıldışı Performans İnançları Envanteri-2, Turner ve diğ. (2016) tarafından performans ortamına yönelik akıldışı inançları ölçmek amacıyla geliştirilen Akıldışı Performans İnançları 
Envanteri'nin (APİE), Turmer ve Allen (2018) tarafından başka bir çalışmada oluşturulmuş kısa formudur. Sporcuların akıldışı performans inançlarını talepkarlık, felaketleştirme, düşük tolerans ve değersizleştirme olmak üzere 4 alt boyutta değerlendirmektedir. Ölçek 5'li likert tipindedir ve 20 maddeden oluşur. Ölçeğin Türkçe uyarlaması Urfa ve Aşçı (2018) tarafından yapılmış ve ölçeğin tamamına ait iç tutarlık katsayısı 0.88, alt boyutlarına ait iç tutarlık katsayısı 0.83 (talepkarlık faktörü) ile 0.86 (düşük tolerans ve değersizleştirme faktörleri) aralığında bulunmuştur. Alt boyutlar ve toplamdan alınan yüksek puan yüksek akıl dışı inanç anlamına gelmektedir (Urfa ve Aşçı 2018). Bu çalışma örneklemine ait iç tutarlık katsayıları ise talepkarlık 0.80 , felaketleştirme 0.82 , düşük tolerans 0.86 ve değersizleştirme 0.75 olarak bulunmuştur.

Verilerin Toplanması: Verilerin toplanması için gerekli kurumlardan izinler alındıktan sonra çalışma kapsamında kullanılacak veri toplama araçları sporculara uygun oldukları zamanlarda gönüllülük esası dikkate alınarak uygulanmıştır. Ölçekler uygulanmadan önce sporculara bilgilendirme ve onam formu doldurtulmuştur. Ölçeklerin doldurulmasına ilişkin bilgiler araştırmacılar tarafından sporculara verilmiştir. Veri toplama süreci ayrıca online olarak da sağlanmıştır. Araştırma için gerekli olan ekler Google Formlar üzerinden sporculara ulaştırılmıştır. Çalışmada kullanılan ölçekler için ilgili araştırmacılardan gerekli izinler ve çalışmanın bilimsel ve etik olarak uygun olduğuna dair onay Marmara Üniversitesi Sağlık Bilimleri Enstitüsü Etik Kurulu’ndan alınmıştır (Protokol No: 13.01.2020/18).

Verilerin Analizi: Verilerin analizinde betimsel istatistik, çoklu hiyerarşik regresyon analizi kullanılmıştır. Verilerin regresyon analizi için uygun olup olmadığı sınanmıştır. Bu bağlamda değişkenler arasında çoklu bağlantılılık, otokorelasyon problemi, doğrusallık ve hata varyanslarının eşit dağılımı (Tabachnick ve Fidell, 2013) incelenmiştir. Çoklu bağlantılılık için Pearson ilişki katsayısı ile değişkenler arasındaki korelasyon incelenmiş ve elde edilen değerler çoklu bağlantılılık için sınır olarak kabul edilen 0.80 seviyesinden (Field, 2009) düşük bulunmuştur. Ayrıca çoklu bağlantılılık durumunun değerlendirilmesi için Varyans Enflasyon Faktörü (VIF) ve Tolerans (TOL) değerlerine bakılmıştır. TOL değerinin 0.10'un altında olması, VIF değerinin ise 10'un üzerinde olması bağımsız değişkenler arasında yüksek ilişki olduğunu belirtmektedir (Dormann ve diğ., 2013). Çalışma kapsamında TOL değeri 0.28 - 0.99 aralığında, VIF değeri ise 1.00 - 3.63 aralığındadır. Bu da tahmin değerleri arasında istatistiksel açıdan anlamlı bir ilişki olmadığını göstermektedir.

Çoklu Hiyerarşik Regresyon Analizi, bağımsız değişkenler olan ruminatif düşünce ve akıldışı inanç düzeylerinin bağımlı değişken olan optimal performans duygu durumunu belirlemedeki rolünü test etmek amacı ile kullanılmıştır. Bu araştırmada çoklu hiyerarşik regresyon analizinde bağımlı değişken olan optimal performans duygu durumunu belirlemek için, kontrol değişkeni olan bağımsız değişkenler cinsiyet, spor türü ve spor deneyimi modele birinci adımda, diğer bağımsız değişken ruminatif düşünce modele ikinci adımda dâhil edilmiştir. Yapılan ikinci regresyon analizinde ise modele ikinci adımda akıldışı inançlar dâhil edilmiştir. Cinsiyet, spor türü ve spor deneyimi kategorik değişken oldukları için analizlere alınmadan önce yapay (dummy) bir değişken olarak cinsiyet; 0 (kız) ve 1 (erkek), spor türü; 0 (takım) ve 1 (bireysel) ve spor deneyimi; 0 (2-9 yıl) ve 1 (10 yıl ve üstü) şeklinde kodlanmıştır.

Yapılan analizlerde SPSS 21 programı kullanılmış olup, anlamlılık düzeyi $\mathrm{p}<0.05$ olarak kabul edilmiştir.

\section{BULGULAR}

Tablo 1'de sporcularda ruminatif düşüncenin optimal performans duygu durumunu yordamadaki rolünü test etmek amacı ile yapılan hiyerarşik çoklu regresyon analizi sonuçları verilmiştir. 
Tablo 1

Ruminatif Düşüncenin Optimal Performans Duygu Durumunu Yordamasına İlişkin Hiyerarşik Regresyon Analizi Bulgularl

\begin{tabular}{|c|c|c|c|c|c|c|c|}
\hline & $\beta$ & $\mathbf{t}$ & $\mathbf{p}$ & $\mathbf{R}$ & $\mathbf{R}^{2}$ & Düzeltilmiş $\mathbf{R}^{2}$ & $F_{(d f)}$ \\
\hline Model 1 & & & & \multirow{4}{*}{0.12} & \multirow{4}{*}{0.02} & \multirow{4}{*}{0.01} & \multirow{4}{*}{$\begin{array}{c}2.02 \\
(3.393)\end{array}$} \\
\hline Cinsiyet & 0.03 & 0.58 & 0.56 & & & & \\
\hline Spor Türü & -0.08 & -1.50 & 0.13 & & & & \\
\hline Spor Deneyimi & 0.09 & 1.79 & 0.07 & & & & \\
\hline Model 2 & & & & \multirow{5}{*}{0.15} & \multirow{5}{*}{0.02} & \multirow{5}{*}{0.01} & \multirow{5}{*}{$\begin{array}{c}2.21 \\
(4.393)\end{array}$} \\
\hline Cinsiyet & 0.02 & 0.35 & 0.72 & & & & \\
\hline Spor Türü & -0.07 & -1.27 & 0.29 & & & & \\
\hline Spor Deneyimi & 0.10 & 1.90 & 0.06 & & & & \\
\hline Ruminatif Düşünce & -0.09 & -1.66 & 0.10 & & & & \\
\hline
\end{tabular}

Birinci adımda modele dâhil edilen cinsiyet, spor türü ve spor deneyiminin özgün katkısı model içerisinde anlamlı değildir $\left(\mathrm{R}=0.12 ; \mathrm{R}^{2}=0.02\right.$; Düzeltilmiş $\left.\mathrm{R}^{2}=0.01 ; \mathrm{F}_{(3,393)}=2.02, \mathrm{p}>0.05\right)$. Modele ikinci adımda dâhil edilen ruminatif düşüncenin özgün katkısı da model içerisinde anlamlı değildir $\left(\mathrm{R}=0.15 ; \mathrm{R}^{2}=0.02 ;\right.$ Düzeltilmiş $\mathrm{R}^{2}=0.01 ; \mathrm{F}_{(4,393)}=2.21$, p>0.05). Analizler, ruminatif düşünce ile optimal performans duygu durumu arasında anlamlı ilişki olmadığını göstermiştir $(\beta=-0.09 ; \mathrm{p}>0.05)$.

Tablo 2

Akıldışı İnanç Alt Boyutlarının Optimal Performans Duygu Durumunu Yordamasına İlişkin Hiyerarşik Regresyon Analizi Bulgularl

\begin{tabular}{|c|c|c|c|c|c|c|c|}
\hline & $\beta$ & $\mathbf{t}$ & $\mathbf{p}$ & $\mathbf{R}$ & $\mathbf{R}^{2}$ & Düzeltilmiş $\mathbf{R}^{2}$ & $\mathbf{F}_{(\mathbf{d f})}$ \\
\hline Model 1 & & & & \multirow{5}{*}{0.12} & \multirow{5}{*}{0.02} & \multirow{5}{*}{0.01} & \multirow{4}{*}{$\begin{array}{c}2.02 \\
(3.393)\end{array}$} \\
\hline Cinsiyet & 0.03 & 0.60 & 0.60 & & & & \\
\hline Spor Türü & -0.08 & -1.50 & 0.14 & & & & \\
\hline Spor Deneyimi & 0.09 & 1.80 & 0.08 & & & & \\
\hline Model 2 & & & & & & & \\
\hline Cinsiyet & 0.05 & 0.97 & 0.34 & \multirow{7}{*}{0.25} & \multirow{7}{*}{0.06} & \multirow{7}{*}{0.04} & \multirow{7}{*}{$\begin{array}{c}3.52 * \\
(7.393)\end{array}$} \\
\hline Spor Türü & -0.07 & -1.32 & 0.19 & & & & \\
\hline Spor Deneyimi & 0.07 & 1.35 & 0.18 & & & & \\
\hline Talepkarlık & 0.13 & 1.39 & 0.17 & & & & \\
\hline Felaketleştirme & -0.18 & -1.87 & 0.06 & & & & \\
\hline Düşük Tolerans & 0.22 & 2.92 & 0.01 & & & & \\
\hline Değersizleştirme & -0.10 & -1.36 & 0.18 & & & & \\
\hline
\end{tabular}

Tablo 2'de ise sporcuların akıldışı inançlarının talepkarlık, felaketleştirme, düşük tolerans ve değersizleştirme alt boyutlarında optimal performans duygu durumunu yordamadaki rolünü test etmek amacı ile yapılan hiyerarşik çoklu regresyon analizi sonuçları verilmiştir.

Birinci adımda modele dâhil edilen cinsiyet, spor türü ve spor deneyiminin özgün katkısı model içerisinde anlamlı değildir $\left(\mathrm{R}=0.12 ; \mathrm{R}^{2}=0.02 ;\right.$ Düzeltilmiş $\left.\mathrm{R}^{2}=0.01 ; \mathrm{F}_{(3,393)}=2.02, \mathrm{p}>0.05\right)$. Modele ikinci adımda dâhil edilen akıldış1 inançların katkısı anlamlıdır ve optimal performans duygu durumunun açıklanmasına katkısı \% 3'tür. Cinsiyet, spor deneyimi, spor türü ile birlikte akıldışı inanç alt boyutları optimal performans duygu durumunun \% 4'ünü açıklamaktadır $\left(\mathrm{R}=0,25 ; \mathrm{R}^{2}=0,06\right.$; Düzeltilmiş $\left.\mathrm{R}^{2}=0,04 ; \mathrm{F}_{(7,393)}=3,52, \mathrm{p}<0.05\right)$. Akıldışı inanç alt boyutlarından düşük tolerans ile optimal performans duygu durumu arasında anlamlı pozitif ilişki bulunmuştur $(\beta=0.22 ; \mathrm{p}<0.05)$. 


\section{TARTISSMA}

$\mathrm{Bu}$ çalışmanın amacı ruminatif düşünce ve akıldışı inanç kavramlarının optimal performans duygu durumunu belirlemedeki rolünün incelenmesidir.

Çalışmadan elde edilen bulgular, sporcularda ruminatif düşüncenin optimal performans duygu durumunun belirleyicisi olmadığını göstermiştir. Diğer bir deyişle, çalışmanın bulguları sporcuların zihnini meşgul eden tekrarlayıcı içsel düşüncelerin, sporcuların yaptığı aktivite ile özdeşleşmeleri, performans sırasında göreve odaklanmaları, kontrol duygularını sürdürebilmeleri, aktiviteye kendilerini kaptırmaları, kendilik farkındalığından uzaklaşıp zaman algılarını yitirmeleri ile ilişkili olmadığını göstermektedir. Elde edilen bu bulguya göre, ruminatif düşüncelerin sporcuların optimal performans duygu durumu yaşama olasılıklarını engelleyen bir faktör olmadığı söylenebilir. Alan yazın incelendiğinde pozitif psikoloji kavramlarından biri olan optimal performans duygu durumun ruminatif düşünce ile arasındaki ilişkiyi ele alan çalışma yapılmadığı görülmektedir. Bu bağlamda çalışmadan elde edilen bu bulgu ruminatif düşünce ile diğer pozitif psikoloji kavramları arasındaki ilişkiden yola çıkılarak irdelenmeye çalışılııışır. Çalışmanın hipotezinin aksine, performans üzerinde olumsuz etkisi olduğu düşünülen ruminatif düşüncenin optimal performans duygu durumuna etkisinin olmaması, alan yazında ruminatif düşünce ile ilişkili olan ve optimal performans duygu durum ile benzer özelliklere sahip bilinçli farkındalık kavramı ile açıklanabilir. Optimal performans duygu durumu ve bilinçli farkındalık, belirli bir görev üzerinde dikkat sağlamayı ve kendini göreve kaptırmayı içerir ve her ikisinde de şimdiki ana odaklanmak vardır (Kaufman ve diğ., 2009; Reid, 2011). Ryan ve Brown'a (2003) göre, bilinçli farkındalığı yüksek olan sporcuların olumlu bir benlik saygısına sahip olmaları, sporcuların öz-bilinç kaybının daha güçlü olmasına ve bunun sonucunda da optimal performans duygu durumunun yaşanmasını sağlar. Bilinçli farkındalık ile optimal performans duygu durum arasındaki benzerlik ve ilişkisel yapı birlikte ele alındığında, bu durumun ruminatif düşünce ile optimal performans duygu durum arasındaki ilişkiyi etkilemiş olabileceği düşünülmüştür. Bunun yanısıra, ruminatif düşünce ile optimal performans duygu durum arasında ilişki olmaması; ruminatif düşünce ile pozitif psikoloji kavramlarından bilinçli farkındalık arasındaki ters yönlü ilişki ile de açıklanabilir. Yapılan çalışmalar bireylerde artan bilinçli farkındalığın, ruminatif düşünce düzeylerinde azalmaya neden olduğunu ortaya koymuştur (Birrer ve diğ., 2012; Borders ve diğ., 2010; Raes ve Williams, 2010). Bunun yansıra, Flett ve diğ. (2016) yaptıkları, bilinçli farkındalığın ruminatif düşüncenin olumsuz etkilerini azalttığını ortaya koyduğu çalışma bulguları da yukarıda bahsi geçen olası nedeni destekler niteliktedir.

Ruminatif düşüncelerin optimal performans duygu durumunun belirleyicisi olmadığı bulgusu ruminatif düşüncenin kuramsal yapısını açıklayan amaca dönük ilerleme teorisine göre de irdelenebilir. Amaca yönelik ilerleme teorisine göre ruminatif düşünce bir öz odaklanma biçimidir ve ruminatif düşüncenin yaşanması hedef tutarsızlıklarını azaltmaya yardımcı olur (Martin ve Tesser, 1996). Bu nedenle ruminatif düşünceler ile bozulması beklenen optimal performans duygu durumu sırasında oluşan göreve odaklanma ve hedeflerin açık ve net olması durumu ruminatif düşüncelerden etkilenmeyebilir. Carver ve Scheier (1990) ise amaca yönelik ilerleme hızında iyileşme olması durumunun, duygu durumda bir iyileşmeye yol açacağını belirtmiş̧tir. Amaca yönelik ilerleme hızında iyileşme olması ile birlikte duygu durumda gerçekleşen bu iyileşme, optimal performans duygu durum sırasında oluşan kontrol duygusunun ruminatif düşünceler ile bozulmamasının nedeni olarak görülebilir. Ayrıca yapılan çalışmalara göre amaca yönelik ruminatif düşünceler her zaman sorunlu duygusal sonuçlara neden olmamaktadır (Watkins, 2008; Roberts ve diğ., 2020). Bu bilgiler ışığında ruminatif düşüncenin optimal performans duygu durumuna olumsuz etkisinin olmaması olası sonuç olabileceği söylenebilir.

Çalışmada elde edilen diğer bir sonuç ise akıldışı inanç alt boyutlarından düşük tolerans ile optimal performans duygu durumu arasında anlamlı pozitif ilişki bulunmasıdır. Diğer bir deyişle, düşük tolerans akıldışı inancı arttıkça, sporcuların 
optimal performans duygu durumu deneyimlemeleri de artmaktadır. Akıldışı inançların düşük tolerans alt boyutundan elde edilen yüksek puan sporcuların başarısızlığa, belirledikleri hedeflere ulaşamamaya ve sürekli gelişim halinde olmamaya karşı tahammülsüzlüklerinin daha fazla olması anlamına gelmektedir. Düşük tolerans akıldışı inancı yüksek sporcuların, hedefleri konusunda netliğe sahip olmaları ve başarısızlık yaşamamak için bu yönde çaba göstermeleri olasıdır ve bu çaba aynı zamanda sporcuların göreve odaklanmalarını sağlar (Harrington, 2005). Optimal performans duygu durumunun alt boyutlarından olan net hedefler, optimal performans duygu durumunu deneyimlemek için önkoşul niteliğindedir (Swann ve diğ., 2012). Bu bağlamda, akıldışı inancın düşük tolerans alt boyutundan yüksek puan alan sporcuların optimal performans duygu durumuna daha kolay ulaşabiliyor olması, bu sporcuların hedeflerine ulaşamamaya, başarılı olamamaya ve kendini geliştirememeye karşı tahammülsüz olmalarından dolayı başarılı olmak için daha fazla istek duymaları ile bu durumu motivasyon kaynağı haline getirerek göreve odaklarının artmasından kaynaklanıyor olabilir (Harrington, 2005). Kısaca düşük tolerans akıldışı inancı nedeni ile başarısızlıktan kaçınan sporcular, hedeflerinin de netliği ile göreve daha fazla odaklanarak optimal performans duygu durumuna ulaşabilirler. Bu durum düşük tolerans akıldışı inancı yüksek olan sporcuların optimal performans duygu durumunu yaşadıklarını gösteren bulguyu açıklar niteliktedir.

Alanyazın incelendiğinde akıldışı inançların her zaman rahatsızlığa yol açmadığı kabul edilse de (Ellis, 1996), Harrington (2005) daha da ileri gitmiş ve akıldışı inançların her zaman işlevsiz olmayabileceğinden yola çıkarak, kaygının bireyleri çalışmaya motive edebileceğini ortaya koymuştur. Harrington'un (2005) çalışması düşük tolerans inancının erteleme davranışını azaltarak bireyleri çalışmaya/göreve yönelttiğini göstermektedir, kısaca akıldışı inançların işlevsel davranışı artırabileceği görülmektedir. Düşük tolerans akıldışı inancının bireyleri göreve yönelttiğini gösteren bu bulgu çalışmamızda düşük tolerans akıldışı inancı arttıkça, optimal performans duygu durumunun yaşanmasını arttırdığ bulgusunu destekler niteliktedir. Bu duruma düşük toleranslı bireylerin maruz kaldıkları kaygı nedeniyle oluşan rahatsızlıktan kaçınmalarının neden olduğu düşünülebilir (Harrington, 2005). Benzer şekilde Chang ve D'Zurilla (1996) düşük toleransın taleplerden ziyade, kaygı ve depresyonu önemli ölçüde yordadığını belirtmiştir. Bu durumda, düşük toleranslı sporcuların göreve odaklanmalarını sağlayarak optimal performans duygu durumuna ulaştıran faktöründe kaygı olduğu söylenebilir. Diğer bir deyişle, düşük tolerans ve kaygı arasındaki bu ilişki, düşük tolerans akıldışı inancı yüksek olan sporcuların kaygı durumundan kaçınmak için göreve yönelmeleri ile optimal performans duygu durumunu daha fazla deneyimlemelerini açıklayabilir.

\section{SONUÇ ve ÖNERILER}

Sonuç olarak elde edilen bulgular, sporcularda ruminatif düşüncenin optimal performans duygu durumunun belirleyicisi olmadığını ve sporcularda akıl dışı inanç alt boyutlarından düşük tolerans ile optimal performans duygu durumu arasında anlamlı pozitif ilişki olduğunu göstermiş̧tir. Başka bir deyişle, ruminatif düşünce optimal performans duygu durumunu deneyimleme üzerinde etkili değilken, akıldışı inanç alt boyutlarından düşük tolerans optimal performans duygu durumun deneyimlenmesini sağlamaktadır. Elde edilen bu bulgular, çalışmanın sınırılıkları dikkate alınarak değerlendirilmelidir. Çalışma kesitsel bir çalışmadır. Bu nedenle, çalışmanın sonuçları neden sonuç ilişkisini net olarak ortaya koyamamaktadır ve bu çalışmanın bulgularının genellenebilirliğini etkilemektedir. Bunun yanısıra, çalışmanın örneklemi atletizm, boks, güreş, halter, karate, okçuluk, tekvando, tenis, yüzme, basketbol, futbol, hentbol, voleybol, ragbi ve sualtı hokeyi branşları ile sınırlandırılmıştır. Bu bağlamda, bu çalışmada elde edilen bulguların satranç ve atıcılık gibi odaklanma ve bilişsel süreçlerin daha ön planda olduğu spor branşları için genellenebilirliği düşüktür. İlerideki çalışmalarda bilişsel öğelerin ön planda olduğu branşlarda bu kavramlar arasındaki ilişki ele alınabilir. Bunun yanı sıra, gelecek çalışmalarda bu kavramlar arasındaki ilişkiyi etkileyebilecek olası düzenleyici değişkenler, örneğin 
bilinçli farkındalık kavramı, ele alınabilir. Çalışmada optimal performans duygu durum ve akıldışı inançlar spor ortamına yönelik ele alınırken, ruminatif düşünce genel yaşam bazında değerlendirilmiştir. İlerideki çalışmalarda sportif performansa özgü olarak ruminatif düşüncenin ölçülmesi bu kavramlar arasındaki ilişkinin irdelenmesine katk1 sağlayabilir. Ayrıca ruminatif düşünceler tekrarlayıcı (brooding) ve yansıtıcı (reflective) olmak üzere iki farklı şekilde sınıflandırılmaktadır. Bu çalışmada ruminatif düşünce değerlendirmesi tekrarlayıcı ruminatif düşünceler üzerinedir. Gelecek çalışmalarda yansıtıcı ruminatif düşünceler ile optimal performans duygu durumu ve akıldışı inançlar ilişkisi de incelenebilir. Optimal performans duygu durumu bu çalışmada alt boyutlar bazında irdelenmemiştir. Gelecek çalışmalarda optimal performans duygu durumunun oluşmasını sağlayan ve optimal performans duygu durumunun özellikleri olarak nitelenen alt boyutlar bağlamında ilişki irdelenebilir. Son olarak, spor alanyazınında sınırlı çalışılmış olan ruminatif düşünce ve akıldışı inanç kavramları zihinsel dayanıklılık, konsantrasyon, bilinçli farkındalık ve benlik algısı gibi kavramlarla birlikte ele alınabilir.

Yazar Katkısı:

1. H. Feyzanur AKSOY: Fikir/Kavram, Tasarım, Denetleme, Veri Toplama ve/veya İşleme, Analiz-Yorum, Makale Yazımı, Eleştirel İnceleme

2. F. Hülya AŞÇI: Fikir/Kavram, Tasarım, Denetleme, Veri Toplama ve/veya İşleme, Analiz-Yorum, Makale Yazımı, Eleştirel İnceleme

\section{Etik Kurul İzni ile İlgili Bilgiler}

Kurul Adı: Marmara Üniversitesi Sağlık Bilimleri Enstitüsü Etik Kurulu

Tarih: 13.01 .2020

Sayı No: 18 


\section{KAYNAKÇA}

1. Ada, E.N., Çetinkalp, Z.K., Altıparmak, M.E., ve Aşçı, F.H. (2018). Flow experiences in physical education classes: The role of perceived motivational climate and situational motivation. Asian Journal of Education and Training, 4(2), 114-120.

2. Altıntaş, A., Kelecek, S., ve Aşçı, F.H. (2013). Elit sporcularda durumsal güdülenme ve optimal performans duygu durumu arasındaki ilişki. Pamukkale Journal of Sport Sciences, 4(4), 14-21.

3. Aras, D., Yiğit, S., Kayam, S., Arslan, E., ve Akça, F. (2020). Bilişsel yorgunluğun egzersiz ve spor performansına etkileri. Spormetre Beden Eğitimi ve Spor Bilimleri Dergisi, 18(1), 1-32.

4. Asakawa, K. (2004). Flow experience and autotelic personality in Japanese college students: How do they experience challenges in daily life? Journal of Happiness Studies, 5(2), 123-154.

5. Birrer, D., Röthlin, P., ve Morgan, G. (2012). Mindfulness to enhance athletic performance: Theoretical considerations and possible impact mechanisms. Mindfulness, 3(3), 235-246.

6. Borders, A., Earleywine, M., ve Jajodia, A. (2010). Could mindfulness decrease anger, hostility, and aggression by decreasing rumination? Aggressive Behavior, 36(1), 28-44.

7. Brinker, J.K., ve Dozois, J.A. (2009). Ruminative thought style and depressed mood. Journal of Clinical Psychology, 65(1), 1-19.

8. Burnette, J.L., Davis, D.E., Green, J.D., Worthington, E.L., ve Bradfield, E. (2009). Insecure attachment and depressive symptoms: The mediating role of rumination, empathy, and forgiveness. Personality and Individual Differences, 46(3), 276-280.

9. Carver, C.S., ve Scheier, M.F. (1990). Origins and functions of positive and negative affect: A control-process view. Psychological Review, 97(1), 19-35.

10. Cervello, E., Moreno, J.A., Villodre, N.A., ve Iglesias, D. (2006). Goal orientation, motivational climate, and dispositional flow of high school students engaged in extracurricular physical activity. Perceptual and Motor Skills, 102(1), 87-92.

11. Chang, E.C., ve D'Zurilla, T.J. (1996). Irrational beliefs as predictors of anxiety and depression in a college population. Personality and Individual Differences, 20(2), 215-219.

12. Crust, L., ve Swann, C. (2011). Comparing two measures of mental toughness. Personality and Individual Differences, 50(2), 217-221

13. Csikszentmihalyi, M. (1975). Beyond boredom and anxiety. San Francisco: Jossey-Bass.

14. Csikszentmihalyi, M. (1990). Flow: The psychology of optimal experience. New York: Harper \& Row.

15. Çağlar, E., Sarı, İ., Aşçı, F.H., Eklund, R.C., ve Jackson, S.A. (2020). Short versions of turkish flow scales: Reliability and validity study. Studia Psychologica, 62(3), 179-197.

16. DiGiuseppe, R.A., ve David, O.A. (2015). Rational emotive behavior therapy. In: HT Prout, AL Fedewa (Ed), Counseling and Psychotherapy with Children and Adolescents: Theory and Practice for School and Clinical Settings, (pp 155-216). John Wiley and Sons.

17. Dormann, C.F., Elith, J., Bacher, S., Buchmann, C., Carl, G., Carré, G., Marquez, J.R.G., Gruber, B., Lafourcade, B., Leitao, P.J., Münkemüller, T., McClean, C., Osborne, P.T., Reineking, B., Schröder, B., Skidmore, A.K., Zurell, D., ve Lautenbach, S. (2013). Collinearity: A review of methods to deal with it and a simulation study evaluating their performance. Ecography, 36(1), 27-46.

18. Dryden, W., ve Branch, R. (2008). Fundamentals of rational emotive behaviour therapy: A training handbook. John Wiley \& Sons.

19. Ellis A. (1996). Responses to criticisms of rational-emotive behavior therapy (REBT). Journal of Rational-Emotive and Cognitive-Behavior Therapy, 14, 97-121

20. Ellis, A., David, D., ve Lynn, S.J. (2009). Rational and urrational beliefs: A historical and conceptual perspective. In: D David, SJ Lynn, A Ellis, eds. Rational and Irrational Beliefs: Research, Theory, and Clinical Practice, (pp 3-22). Oxford University Press.

21. Field, A. (2009). Discovering statistics using SPSS (3rd Eds). London: Sage Publications Ltd.

22. Flett, A.L., Haghbin, M., Pychyl, T.A. (2016). Procrastination and depression from a cognitive perspective: An exploration of the associations among procrastinatory automatic thoughts, rumination, and mindfulness. Journal of Rational-Emotive and Cognitive-Behavior Therapy, 34(3), $169-186$

23. Gladwell, M. (2008). The 10000 hour-rule. In: Outliers, (35-68). New York: Little, Bown and Co.

24. González-Cutre, D., Sicilia, A., Moreno, J.A., ve Fernández-Balboa, J.M. (2009). Dispositional flow in physical education: Relationships with motivational climate, social goals, and perceived competence. Journal of Teaching in Physical Education, 28, 422-440.

25. Gözmen, A., ve Aşçı, F.H. (2016). Sporcularda optimal performans duygu durumunun yordanmasında beş faktörlü kişilik özelliklerinin ve mükemmeliyetçiliğin rolü. Spor Bilimleri Dergisi, 27(1), 40-48.

26. Hamilton, J.S., ve Schutte, N.S. (2016). The role of adherence in the effects of a mindfulness intervention for competitive athletes: Changes in mindfulness, flow, pessimism, and anxiety. Journal of Clinical Sport Psychology, 10, 99-117.

27. Harrington, N. (2005). It's too difficult! Frustration intolerance beliefs and procrastination. Personality and Individual Differences, 39, 873-883. 
28. Jackman, P.C., Hawkins, R.M., Crust, L., ve Swann, C. (2019). Flow states in exercise: A systematic review. Psychology of Sport and Exercise, 45, 1-16.

29. Jackman, P.C., Van Hout, M.C., Lane, A., ve Fitzpatrick, G. (2014). Experiences of flow in jockeys during flat-race conditions. International Journal of Sport and Exercise Psychology, 13(3), 205-223.

30. Jackson, S.A., ve Csikszentmihalyi, M. (1999). Flow in sports. Champaign: Human Kinetics.

31. Jackson, S.A., ve Eklund, R.C. (2004). The flow scales manual. Morgantown, WV: Fitness Information Technology.

32. Jackson, S.A, Martin, A.J., ve Eklund, R.C. (2008). Long and short measures of flow: Examining construct validity of the FSS-2, DFS-2, and new brief counterparts. Journal of Sport and Exercise Psychology, 30, 561-587.

33. Jackson, S.A., ve Roberts, G.C. (1992). Positive performance states of athletes: Toward a conceptual understanding of peak performance. The Sport Psychologist, 6(2), 156-171.

34. Josefsson, T., Ivarsson, A., Lindwall, M., Gustafsson, H., Stenling, A., Böröy, J., Mattsson, E., Carnebratt, J., Sevholt, S., ve Falkevik, E. (2017). Mindfulness mechanisms in sports: Mediating effects of rumination and emotion regulation on sport-specific coping. Mindfulness, 5(1), 18-35.

35. Karatepe, H.T., Yavuz, F., ve Türkcan, A. (2013). Ruminatif düşünme biçimi ölçeği’nin türkçe geçerlilik ve güvenilirliği. Klinik Psikofarmakoloji Bülteni, 23(3), 231-41.

36. Kaufman, K.A., Glass, C.R., ve Arnkoff, D.B. (2009). Evaluation of mindful sport performance enhancement (MSPE): A new approach to promote flow in athletes. Journal of Clinical Sports Psychology, 4, 334-356.

37. Martin, L.L., ve Tesser, A. (1996). Some ruminative thoughts. In: Wyer RS, eds. Advances in Social Cognition (pp 1-47). Mahwah, NJ: Lawrence Erlbaum.

38. Moneta, G.B. (2004). The flow experience across cultures. Journal of Happiness Studies, 5(2), 115-121

39. Murcia, J.A.M., Gimeno, E.C., ve Coll, D.G. (2008). Relationships among goal orientations, motivational climate and flow in adolescent athletes: Differences by gender. The Spanish Journal of Psychology, 11(1), 181-191.

40. Raes, F., ve Williams, J.M.G. (2010). The relationship between mindfulness and uncontrollability of ruminative thinking. Mindfulness, 1, 199203.

41. Reid, D. (2011). Mindfulness and flow in occupational engagement: Presence in doing. Canadian Journal of Occupational Therapy, 78, 50-56.

42. Roberts, H., Moberly, N.J., Cull, T., Gow, H., Honeysett, M., ve Dunn, BD. (2020). Short-term affective consequences of specificity of rumination about unresolved personal goals. Journal of Behavior Therapy and Experimental Psychiatry, 66, 101519.

43. Rogatko, T.P. (2009). The influence of flow on positive affect in college students. Journal of Happiness Studies, 10(2), 133-148.

44. Ryan, R.M., ve Brown, K.W. (2003). Why we don't need self-esteem: On fundamental needs, contingent love, and mindfulness. Psychological Inquiry, 14(1), 71-76.

45. Stavrou, N.A., Jackson, S.A., Zervas, Y., ve Karteroliotis, K. (2007). Flow experience and athletes' performance with reference to the orthogonal model of flow. The Sport Psychologist, 21, 438-457.

46. Swann, C., Keegan, R.J., Piggott, D., ve Crust, L. (2012). A systematic review of the experience, occurrence, and controllability of flow states in elite sport. Psychology of Sport and Exercise, 13(6), 807-819.

47. Swann, C., Piggott, D., Crust, L., Keegan, R.J., ve Hemmings, B. (2014). Exploring the interactions underlying flow states: A connecting analysis of flow occurrence in European Tour golfers. Psychology of Sport and Exercise, 16, 60-69.

48. Tabachnick, B.G., ve Fidell, L.S. (2013). Using multivariate statistics (6th ed.). Boston, MA: Pearson.

49. Turner, M.J., ve Allen, M.S. (2018). Confirmatory factor analysis of the irrational performance beliefs inventory (iPBI) in a sample of amateur and semi-professional athletes. Psychology of Sport and Exercise, 35, 126-130.

50. Turner, M.J., Allen, M.S., Slater, M.J., Barker, J.B., Woodcock, C., Harwood, C.G., ve McFayden, K. (2016). The development and initial validation of the irrational performance beliefs inventory (iPBI). European Journal of Psychological Assessment, 32, 1-7.

51. Ullén, F., Manzano, Ö., Almeida, R., Magnusson, K.E., Pedersen, N.L., Nakamura, J., Csíkszentmihályi, M., ve Madison, G. (2012). Proneness for psychological flow in everyday life: Associations with personality and intelligence. Personality and Individual Differences, 52, 167-172.

52. Urfa, O., Aşçı, F.H. (2018). Akıldışı performans inançları envanteri-2'nin psikometrik özelliklerinin sınanması. Psikoloji Çalışmaları, 38(2), 219-236.

53. Watkins, R. (2008). Constructive and unconstructive repetitive thought. Psychological Bulletin, 134(2), 163-206.

54. Wiggins, M., ve Freeman, P. (2000). Anxiety and flow: an examination of anxiety direction and the flow experience. International Sports Journal, 4, 78-87.

55. Ysseldyk, R., Matheson, K., ve Anisman, H. (2007). Rumination: Bridging a gap between forgivingness, vengefulness, and psychological health. Personality and Individual Differences, 42, 1573-1584. 